\title{
Epidural steroid injections compared with gabapentin for lumbosacral radicular pain: multicenter randomized double blind comparative efficacy study
}

\author{
Steven P Cohen, ${ }^{1,2}$ Steven Hanling, ${ }^{3}$ Mark C Bicket, ${ }^{4}$ Ronald L White, ${ }^{5}$ Elias Veizi, ${ }^{6}$ Connie Kurihara, \\ Zirong Zhao, ${ }^{8,9}$ Salim Hayek, ${ }^{10}$ Kevin B Guthmiller, ${ }^{11,12}$ Scott R Griffith, ${ }^{13}$ Vitaly Gordin, ${ }^{14}$ \\ Mirinda Anderson White, ${ }^{15}$ Yakov Vorobeychik, ${ }^{16}$ Paul F Pasquina ${ }^{17}$
}

\section{ABSTRACT}

OBJECTIVE

To evaluate whether an epidural steroid injection or gabapentin is a better treatment for lumbosacral radiculopathy.

\section{DESIGN}

A multicenter randomized study conducted between 2011 and 2014. Computer generated randomization was stratified by site. Patients and evaluating physicians were blinded to treatment outcomes.

SETTINGS

Eight military, Veterans Administration, and civilian hospitals.

\section{PARTICIPANTS}

145 people with lumbosacral radicular pain secondary to herniated disc or spinal stenosis for less than four years in duration and in whom leg pain is as severe or more severe than back pain.

\section{INTERVENTIONS}

Participants received either epidural steroid injection plus placebo pills or sham injection plus gabapentin.

MAIN OUTCOME MEASURES

Average leg pain one and three months after the injection on a 0-10 numerical rating scale. A positive outcome was defined as $a \geq 2$ point decrease in leg pain coupled with a positive global perceived effect. All patients had one month follow-up visits; patients whose condition improved remained blinded for their three month visit.

\section{RESULTS}

There were no significant differences for the primary outcome measure at one month (mean pain score 3.3 (SD 2.6) and mean change from baseline -2.2 (SD 2.4) in epidural steroid injection group versus 3.7 (SD 2.6) and -1.7 (SD 2.6) in gabapentin group; adjusted difference $0.4,95 \%$ confidence interval -0.3 to $1.2 ; \mathrm{P}=0.25)$ and three months (mean pain score 3.4 (SD 2.7) and mean

\section{WHAT IS ALREADY KNOWN ABOUT THIS TOPIC}

Gabapentin and epidural steroid injections are often used to treat lumbosacral radiculopathy and can provide benefit for a subset of patients, but we do not know which treatment works better

\section{WHAT THIS STUDY ADDS}

Both epidural steroid injections and gabapentin treatment resulted in significant improvements in pain scores and functional capacity

Although epidural steroid injections might be superior to gabapentin in some outcome measures, the differences are small and generally short lived change from baseline -2.0 (SD 2.6) versus 3.7 (SD 2.8) and -1.6 (SD 2.7), respectively; adjusted difference 0.3 , -0.5 to $1.2 ; \mathrm{P}=0.43)$. Among secondary outcomes, one month after treatment those who received epidural steroid injection had greater reductions in worst leg pain $(-3.0$, SD 2.8) than those treated with gabapentin $(-2.0$, SD 2.9; $P=0.04)$ and were more likely to experience a positive successful outcome $(66 \% \mathrm{v} 46 \%$; number needed to treat $=5.0,95 \%$ confidence interval 2.8 to 27.0 ; $\mathrm{P}=0.02$ ). At three months, there were no significant differences between treatments.

\section{CONCLUSIONS}

Although epidural steroid injection might provide greater benefit than gabapentin for some outcome measures, the differences are modest and are transient for most people.

\section{TRIAL REGISTRATION}

ClinicalTrials.gov Identifier: NCT01495923.

\section{Introduction}

The physical, socioeconomic, and psychological impact of low back pain is enormous. Low back pain has been the leading cause of years lost to disability over the past several decades, ${ }^{1}$ with a lifetime prevalence that ranges between $50 \%$ and $90 \% .^{23}$ The economic cost is estimated to exceed $\$ 100$ bn a year in the United States ( $€ 67 \mathrm{bn}, € 93 \mathrm{bn}$ ), over half of which can be attributed to lost productivity. ${ }^{34}$ Efforts to deal with the worldwide burden posed by low back pain have become an international priority.

The classification of back pain is perhaps the most important distinction for clinicians to make as it influences investigation and treatment decisions at all levels of care. ${ }^{5}$ Since the development of validated instruments to categorize low back pain, ${ }^{67}$ studies have determined that the proportion of chronic cases that are predominantly neuropathic (that is, sciatica, radicular pain from a herniated disc, or neurogenic claudication from spinal stenosis) ranges between $17 \%$ and 55\%, ${ }^{7-11}$ with one review finding a median prevalence rate of $41 \%{ }^{12}$ Whereas the presence of neuropathic symptoms portends a more negative prognosis for acute episodes, ${ }^{13}$ lumbosacral radicular pain might be more responsive to procedural interventions than nonspecific back pain. ${ }^{1214}$

Epidural steroid injections are the most commonly performed procedure for pain relief in the world, ${ }^{15}$ being more commonly used and more effective for radicular pain than mechanical spine pain. ${ }^{1216}$ Although mixed, most controlled studies have also 
found pharmacotherapy with gabapentinoids can be effective for lumbosacral radicular pain. ${ }^{17-21}$

Numerous controlled trials have been performed to evaluate epidural steroid injections and drug treatment in people with low back pain, with review articles generally reporting modest effects. ${ }^{122}$ Yet for clinicians, the more relevant question is not whether a real treatment is better than a sham treatment, but which treatment is more effective. ${ }^{23}$

Several small randomized open label studies have looked at epidural steroid injections compared with drug treatment. One study showed superiority for a single epidural steroid injection at one month but not later follow-up compared with tramadol and a muscle relaxant. ${ }^{24}$ A second study showed that a single caudal epidural steroid injection provided better pain relief than non-steroidal anti-inflammatory drugs through three months. ${ }^{25}$ Neither study evaluated first line adjuvant treatments (such as gabapentin) as a comparison group. A more recent three armed multicenter study was performed in 169 patients with cervical radiculopathy. Over six months participants received nortriptyline and/or gabapentin plus physical therapies, up to three cervical epidural steroid injections, or combination treatment in which they received both injections and conservative care. They found that the combination group experienced a higher success rate at three months but not six months. ${ }^{26}$ Although these studies might simulate real life decisions facing clinicians, the fact that none were blinded precludes any conclusions regarding efficacy. We investigated a single epidural steroid injection compared with gabapentin in patients with lumbosacral radicular pain in a double blinded fashion.

\section{Methods}

\section{Participants and settings}

The study sites were four joint service military treatment facilities, three of which serve as teaching hospitals (Walter Reed, San Diego, and San Antonio) and one of which is located in Europe; a Veteran's Administration hospital; and three civilian teaching hospitals (Johns Hopkins, Case Western, and Penn State).

All participants were treated between 15 December 2011 and 10 June 2014. Inclusion criteria were age $\geq 17$; an average score for radicular leg pain of $\geq 4$ on a $0-10$ numerical rating scale over the preceding week or $3 / 10$ if the leg pain was as bad as or worse than back pain; current symptoms had lasted for more than six weeks and up to four years; and signs (such as straight leg raising test) and/or symptoms (such as lower leg pain) of lumbosacral radicular pain. All participants were also required to have findings of a herniated disc or spinal stenosis on magnetic resonance imaging, concordant with their presentation. Patients were permitted to have symptoms in more than one dermatome.

Exclusion criteria were neuropathic pain for more than four years in duration; previous failed trial with, or adverse reaction to, gabapentin or pregabalin; epidural steroid injections within the past three years; cauda equina syndrome; referrals for surgical evaluation; previous lumbar spine surgery; pregnancy; allergic reaction to contrast dye; known secondary gain (such as active litigation); active infection; and serious medical (such as poorly controlled diabetes, cirrhosis, recent myocardial infarction, congestive heart failure, or unstable angina) or psychiatric condition (such as dementia, poorly controlled post-traumatic stress syndrome as indicated by a score $\geq 44$ on the post-traumatic stress disorder checklist, ${ }^{27}$ substance abuse, somatization disorder, or depression as indicated by a Beck Depression score $\geq 21^{28}$ ) that might preclude an optimal response to treatment. Because our intention was to evaluate the relative effects of two commonly used treatments for radicular pain, we also excluded patients with neurogenic claudication from spinal stenosis who did not report lower leg pain (that is, those who had only weakness or paresthesias). Although heterogeneity is often desirable in comparative effectiveness trials, we performed briefings, debriefings, full time access to a senior investigator, and at one site practice enrollments to enhance selection consistency.

\section{Randomization and interventions}

We randomized 145 participants in a 1:1 ratio by computer generated randomization tables. An investigator physician enrolled participants, stratified by study site. Research nurses performed allocation in groups of 36 at Walter Reed and Johns Hopkins as these sites were expected to enroll more patients, and in groups of 18 at other sites, with treatment allocated with a sequentially numbered opaque sealed envelope before injection. Larger allocation blocks were used to promote allocation concealment with investigators. Participants at each site were suballocated separately on a 1:1 ratio based on the type of epidural steroid injection they received: those with unilateral pain received unilateral transforaminal epidural steroid injections, while those with bilateral pain underwent interlaminar epidural steroid injections. The patient, research nurse, and evaluating physician were blinded to assignment.

\section{Epidural injections}

A board certified pain medicine physician conducted or supervised all procedures using fluoroscopic guidance. The segmental level at which the injection was administered was selected based on signs, symptoms, and radiological findings. For interlaminar injections, a Tuohy needle was inserted in or near the midline and advanced into the epidural space with image guidance in the anteroposterior and lateral views by using the loss of resistance technique. For transforaminal epidural steroid injections, a 22 gauge spinal needle was inserted coaxially into the upper part of the targeted foramina with the imagine intensifier positioned in an oblique plane. Correct placement was confirmed with the injection of contrast, which showed bilateral spread for all interlaminar injections and proximal epidural uptake for all transforaminal procedures. Once the physician was satisfied with the pattern of contrast spread, a solution consisting of $60 \mathrm{mg}$ of depomethylprednisolone $+1 \mathrm{~mL}$ of $0.25 \%$ bupivacaine was administered. 
For those who received interlaminar injections, the injectate was diluted in normal saline to a volume of $4 \mathrm{~mL}$; in the transforaminal subgroup, the total volume administered was $3 \mathrm{~mL}$. Whereas some physicians routinely perform multilevel transforaminal injections, we limited our procedures to a single level to minimize risks because there are no controlled studies validating the use of more than one injection and because a well placed transforaminal epidural steroid injection generally spreads to multiple levels. ${ }^{29} 30$

\section{Sham injections and maintenance of blinding}

Participants were instructed ahead of time that they might or might not experience paresthesias during the procedure and were visually shielded from the image screen. The same technique (such as trajectory and use of multiplanar fluoroscopy) was used for injections except in sham injections the needle was positioned $1-2 \mathrm{~cm}$ proximal to the epidural space into the posterior ligaments. A small volume of saline was then injected in lieu of contrast, followed by an additional $3 \mathrm{~mL}$ to simulate the injectate. A generic note was entered into the medical record without radiographs.

\section{Pharmacotherapy}

A central research pharmacy over-capsulated $300 \mathrm{mg}$ gabapentin and placebo capsules to appear identical. Before each shipment, the capsules were tested to ensure potency, or lack thereof for group 2. Titration schedules were prepared on a case-to-case basis in accordance with standard practice, but dosing targets generally ranged from $1800 \mathrm{mg} /$ day to $3600 \mathrm{mg} /$ day three times a day. Drugs were generally up-titrated over a period of 15 to 24 days, with the only caveat being that a therapeutic dose range had to be obtained at least five days before follow-up.

\section{Co-interventions, outcome measures, follow-up, and missing data}

No contact with the investigative team was permitted during the study. Tramadol and non-steroidal antiinflammatory drugs could be prescribed on an "as needed" basis as rescue medications (or opioids could be increased by up to $20 \%$ for those taking opioids), but no other co-interventions were permitted. Participants were provided with instructions on how to taper their analgesic drugs based on response. An investigator blinded to treatment carried out the first follow-up visit one month after the start of treatment. The primary outcome measure was the average leg pain score on a 0-10 numerical rating scale recorded at one and three months, reflecting the average pain experienced during the week before follow-up. Predefined secondary outcome measures included worst leg pain over the past week, average and worst back pain, score on the Oswestry disability index (version 2.0, MODEMS, Des Plaine, IL), ${ }^{31}$ adverse effects and complications, reduction in analgesic drugs ( $>20 \%$ reduction in opioid use or complete cessation of non-opioid analgesics), and global perceived effect, which was defined as not requiring further non-rescue interventions along with an affirmative response to the following two statements: ${ }^{32}$ "My pain has improved/ worsened/stayed the same since my last visit" and "I am satisfied/not satisfied with the treatment I received and would/would not recommend it to others."

Because patients cannot accurately distinguish between neuropathic pain (which is more likely to respond to epidural steroid injection and gabapentin) ${ }^{1233}$ and mechanical pain, we separately recorded leg (neuropathic) and back (mechanical) pain scores as surrogates. Whereas a small percentage of cases of axial back pain might be neuropathic in nature, ${ }^{34}$ and many forms of mechanical pain such as facet arthropathy and degenerative disc disease can radiate into the leg, ${ }^{35}$ validated instruments have shown that leg pain emanating from the back is generally indicative of radicular pain. ${ }^{7}$

The Oswestry disability index is a 10 question survey used to assess function in people with low back and/or leg pain in which higher scores indicate greater levels of disability. The classification of spinal stenosis was made if the participant had moderate or severe canal stenosis $(<12 \mathrm{~mm})$ not attributable to a herniated disc. We assessed complications by asking fixed and open ended questions one day after injections and at all follow-up visits. In addition to individual variables, we predesignated a positive composite outcome (that is, successful procedure) to be a decrease of $\geq 2$ points in average leg pain score coupled with a positive global perceived effect. ${ }^{36}$

In those individuals who experienced a positive outcome at one month, the final follow-up occurred at three months. In these individuals, in addition to rescue medications, the study drug could also be titrated upwards. For ethical reasons, those with a negative outcome at one month left the study "per protocol" to receive non-study interventions, which is consistent with other randomized interventional studies. ${ }^{26} 323738$ We imputed missing data points for pain scores, Oswestry disability index, and the composite outcome using the "last observation carried forward" method, which can underestimate effect sizes when "dropouts" occur because of lack of efficacy. ${ }^{39}$

\section{Statistical analysis}

We used an intention to treat strategy for all analyses. We calculated differences in treatment effects and 95\% confidence intervals for pain and disability scores with analysis of covariance (ANCOVA) adjusting for baseline values of outcome measures. An indicator of the treatment group was coded such that positive values favored the epidural steroid injection group. No correction was prespecified for multiple comparisons. Because of a difference in sex distribution at baseline, we adjusted post hoc analysis of outcomes for sex. We used logistic regression models to compare the proportion of patients with adverse events in the first month and factors associated with binary outcomes in post hoc analysis. We used Poisson regression models with robust standard errors to analyze adverse event rates. Effectiveness of blinding in each treatment group was evaluated by using two indices. In the James blinding index ${ }^{40}$ (range $0-1), 0$ indicates total absence of blinding, 1 indicates 


\begin{tabular}{|c|c|c|}
\hline Characteristic & $\begin{array}{l}\text { Epidural steroid } \\
\text { injection }(\mathrm{n}=73)\end{array}$ & $\begin{array}{l}\text { Gabapentin } \\
(n=72)\end{array}$ \\
\hline Mean (SD age (years) & $43.8(14.0)$ & $41.7(11.9)$ \\
\hline Women* & $25(34)$ & $13(18)$ \\
\hline \multicolumn{3}{|l|}{ Duration of pain: } \\
\hline <3 months: & $11(15)$ & $15(21)$ \\
\hline $3-<$ months & $26(36)$ & $27(38)$ \\
\hline $1-3$ years & $27(37)$ & $23(32)$ \\
\hline$>3$ years & $9(12)$ & $7(10)$ \\
\hline \multicolumn{3}{|l|}{ Treatment with opioids: } \\
\hline None & $54(74)$ & $55(7)$ \\
\hline$<60$ morphine equivalents/day & $16(22)$ & $14(19)$ \\
\hline$\geq 60$ morphine equivalents/day & $3(4)$ & $3(4)$ \\
\hline Mean (SD) oral morphine equivalents among opioid users (mg/day) & $28.7(34.8)$ & $38.5(53.0)$ \\
\hline \multicolumn{3}{|l|}{ Diagnosis: } \\
\hline Herniated nucleus pulposus & $63(85)$ & $65(90)$ \\
\hline Spinal stenosis & $10(14)$ & $7(10)$ \\
\hline \multicolumn{3}{|l|}{ Active duty military: } \\
\hline Any & $38(52)$ & $41(57)$ \\
\hline Enlisted & $26(36)$ & $30(42)$ \\
\hline Officer & $12(16)$ & $11(15)$ \\
\hline \multicolumn{3}{|l|}{ Inciting event: } \\
\hline None & $42(58)$ & $41(60)$ \\
\hline Motor vehicle crash & $1(1)$ & $1(1)$ \\
\hline Fall & $5(7)$ & $9(13)$ \\
\hline Lifting & $13(18)$ & $6(8)$ \\
\hline Sports/training & $8(11)$ & $13(18)$ \\
\hline Othert & $4(6)$ & $2(3)$ \\
\hline Pain related to deployment & $10(14)$ & $6(8)$ \\
\hline Current smoker $\neq$ & $15(21)$ & $13(18)$ \\
\hline Obesity & $13(18)$ & $19(26)$ \\
\hline \multicolumn{3}{|l|}{ Psychiatric comorbidity: } \\
\hline None & $56(77)$ & $49(68)$ \\
\hline Mood & $9(12)$ & $12(17)$ \\
\hline Anxiety & $7(10)$ & $6(8)$ \\
\hline Substance abuse & $3(4)$ & $4(6)$ \\
\hline Post-traumatic stress disorder & $1(1)$ & $4(6)$ \\
\hline Other§ & $1(1)$ & $3(4)$ \\
\hline Multiple diagnoses & $4(6)$ & $6(8)$ \\
\hline \multicolumn{3}{|l|}{ Injection approach: } \\
\hline Interlaminar & $11(15)$ & $12(17)$ \\
\hline Transforaminal & $62(85)$ & $60(83)$ \\
\hline \multicolumn{3}{|l|}{ Level of injection: } \\
\hline L2-3 & $1(1)$ & 0 \\
\hline L3-4 & $1(1)$ & $2(3)$ \\
\hline L4-5 & $22(30)$ & $18(25)$ \\
\hline L5-S1 & $44(60)$ & $46(64)$ \\
\hline S1 & $5(7)$ & $6(8)$ \\
\hline \multicolumn{3}{|l|}{ Mean (SD) baseline pain scores $\uparrow:$} \\
\hline Average leg pain & $5.4(2.1)$ & $5.4(1.9)$ \\
\hline Worst leg pain & $7.9(1.7)$ & $7.8(2.0)$ \\
\hline Average back pain & $5.0(2.6)$ & $4.7(2.4)$ \\
\hline Worst back pain & $7.0(2.6)$ & $7.0(2.9)$ \\
\hline Oswestry disability score & $39.8(15.3)$ & $39.8(14.7)$ \\
\hline
\end{tabular}

*Significant difference between two groups $\left(\mathrm{P}=0.027\right.$ by $\chi^{2}$ test).

tIncludes post-surgical, pregnancy, spinal tap, and work related.

fIncludes three participants who chew tobacco products.

§Includes attention deficit hyperactivity disorder and obsessive compulsive disorder.

१Based on 0-10 numerical rating scale scores. complete blinding, and 0.5 indicates completely random blinding. In the Bang blinding index ${ }^{41}$ (range $-1-1$ ), -1 indicates that all patients guessed the incorrect treatment, 0 indicates all patients randomly guessed, and 1 indicates all patients guessed the correct treatment. We conducted subgroup analyses to ascertain which demographic and clinical variables were associated with outcome. Variables examined included etiology (such as stenosis $v$ herniated disc), level of injection, pain duration $\geq 3$ months, injection type (for instance, transforaminal epidural steroid injection for unilateral pain $v$ interlaminar epidural steroid injection for bilateral pain), smoking status, military status, presence of psychiatric disease, obesity, age, sex, and gabapentin dose. We had intended to examine the effect of inciting events related to war, such as traumatic brain injury, but there were too few patients to render any analysis meaningful. We used Bonferroni-corrected significance thresholds for post hoc subgroup analyses, with corrected $P$ values calculated as 0.05 divided by the number of comparisons being made. All other reported $P$ values were based on two sided tests, with $<0.05$ considered significant.

The study was powered to evaluate the effectiveness of epidural steroid injections compared with gabapentin. Assumptions include a difference of 1 point in pain scores between groups at one month, standard deviation of each group of 2 based on data from previous studies, a retention rate of $87 \%$, and a two sided $\alpha$ level of 0.05 . Although a $30 \%$ or 2 point decrease in pain has been shown to represent a clinically meaningful benefit to an individual patient, the same IMMPACT (Initiative on Methods, Measurement and Pain Assessment in Clinical Trials) guidelines note that smaller differences between groups can be considered to be clinically important in clinical trials. ${ }^{36}$ We chose a 1 point difference in pain scores because it is consistent with US Food and Drug Administration requirements for approval of adjuvant analgesic drugs for low back pain and gabapentin for neuropathic pain. ${ }^{4243}$

\section{Patient involvement}

Although non-scientists from the surrounding communities served on many of the approving review boards at participating institutions, patients did not participate in the design of this study. All participants will receive the results of the study and a copy of the final manuscript from their study team by email or post.

\section{Results}

We assessed 348 potential participants, of whom 147 were eligible for inclusion and agreed to participate. Of these, 145 were assigned to receive either an epidural steroid injections and sham drug $(n=73)$ or gabapentin and a sham injection $(n=72)$. The two groups were similar with respect to baseline characteristics, except that the epidural steroid injection group contained more women (table 1, figure).

\section{Outcomes}

At one month, both the epidural steroid injection group and the gabapentin group experienced improvement in 


\section{Patients assessed for eligibility $(n=348)$}

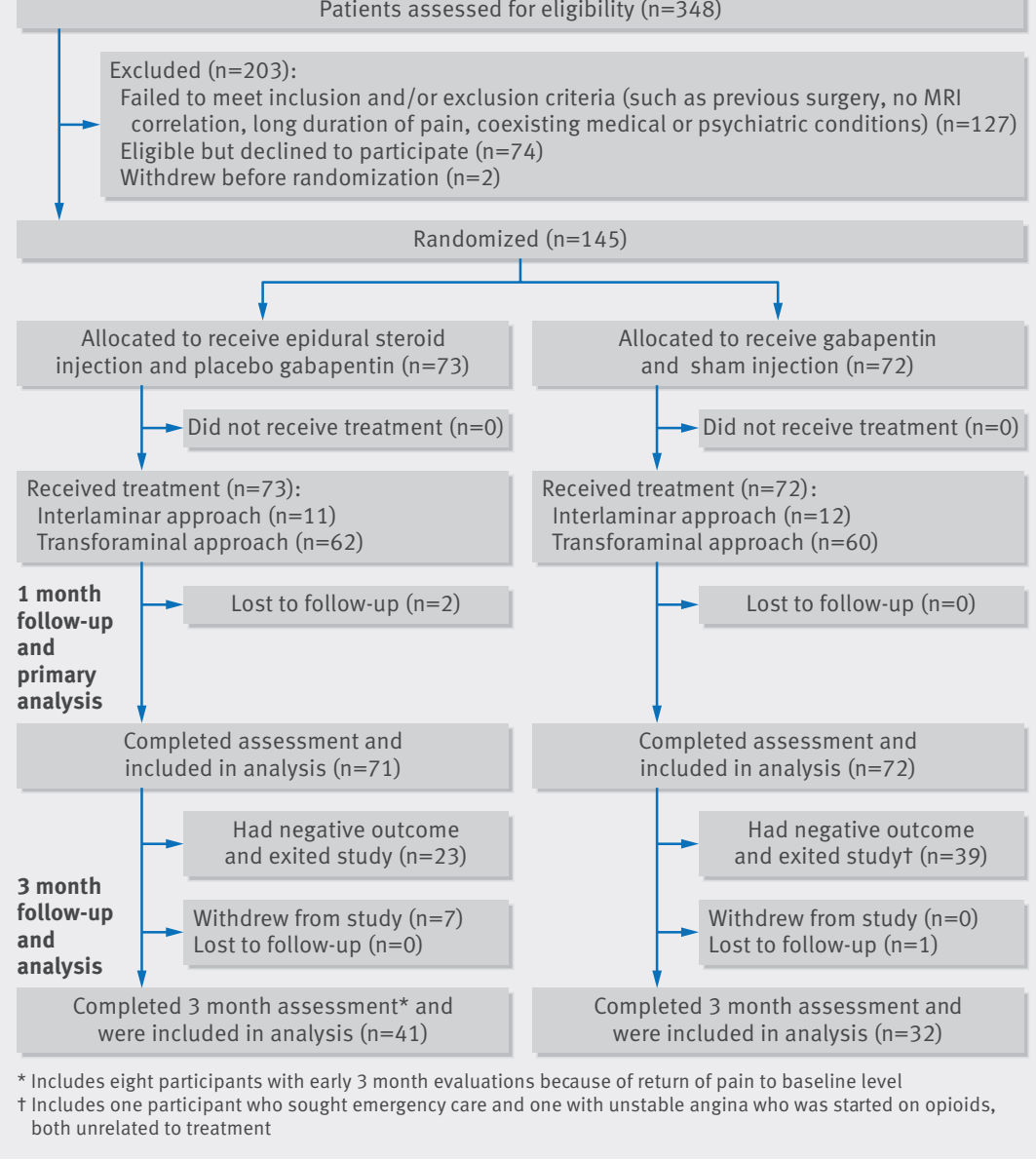

Flow of progress of participants through clinical trial of epidural steroid injections and gabapentin in people with lumbosacral radicular pain the average leg pain score (mean 3.3 points (SD 2.6) and mean change from baseline -2.2 points (SD 2.4) in epidural steroid injection group versus 3.7 points (SD 2.6) and -1.7 points (SD 2.6) in gabapentin group), but no significant difference between groups was observed (adjusted difference 0.4 points, 95\% confidence interval -0.3 to $1.2 ; \mathrm{P}=0.25$ ) (table 2 ). At three months, improvements in average leg pain score persisted (mean 3.4 points (SD 2.7) and -2.0 points (SD 2.6) versus mean 3.7 points (SD 2.8) and -1.6 points (SD 2.7), respectively), but again with no significant difference between groups (0.3 points, -0.5 to $1.2 ; \mathrm{P}=0.43$ ).

For secondary outcome measures, there were small differences between groups favoring epidural steroid injections at one month for worst leg pain score (adjusted difference 0.9 points, 95\% confidence interval 0.0 to 1.9; $\mathrm{P}=0.04$ (table 2)) and successful outcome (66\% and $46 \%, \mathrm{P}=0.02$ (table 3 ); number needed to treat 5.0, 95\% confidence interval 2.8 to 27.0 ). For average back pain at one month, there was a moderate improvement for the epidural steroid injections group (-1.5, SD 1.9) and a mild improvement for the gabapentin group (-1.1, SD 2.3), but the differences were not significant (adjusted difference 0.3 points, -0.4 to 0.9 ; $\mathrm{P}=0.45$ ) (table 2). No significant differences were observed for outcomes at three months or for patients proceeding to surgery within one year of enrollment (9 $(13 \%)$ in epidural steroid injection group $v 10(15 \%)$ in gabapentin group; $\mathrm{P}=0.73$ ) (table 3 ).

\section{Factors associated with outcome and post hoc analyses}

In subgroup analyses, military officers were more likely to experience a positive outcome than either enlisted

Table 2 | Outcomes related to pain and disability in people with lumbosacral radicular pain according to treatment with epidural steroid injections or gabapentin*

\begin{tabular}{|c|c|c|c|c|c|c|c|c|}
\hline & \multicolumn{3}{|c|}{ Epidural steroid injection } & \multicolumn{3}{|c|}{ Gabapentin } & \multicolumn{2}{|l|}{ Treatment comparison } \\
\hline & $\begin{array}{l}\text { No of } \\
\text { patients }\end{array}$ & $\begin{array}{l}\text { Overall } \\
\text { mean (SD) }\end{array}$ & $\begin{array}{l}\text { Mean change } \\
\text { from baseline }\end{array}$ & $\begin{array}{l}\text { No of } \\
\text { patients }\end{array}$ & $\begin{array}{l}\text { Overall } \\
\text { mean (SD) }\end{array}$ & $\begin{array}{l}\text { Mean change } \\
\text { from baseline }\end{array}$ & $\begin{array}{l}\text { Adjusted difference } \\
(95 \% \mathrm{Cl}) \dagger\end{array}$ & Pvalue \\
\hline \multicolumn{9}{|c|}{ Average leg pain: } \\
\hline Baseline & 73 & $5.4(2.1)$ & - & 72 & $5.4(1.9)$ & - & - & - \\
\hline 1 month & 73 & $3.3(2.6)$ & $-2.2(2.4)$ & 72 & $3.7(2.6)$ & $-1.7(2.6)$ & $0.4(-0.3$ to 1.2$)$ & 0.25 \\
\hline 3 months & 73 & $3.4(2.7)$ & $-2.0(2.6)$ & 72 & $3.7(2.8)$ & $-1.6(2.7)$ & $0.3(-0.5$ to 1.2$)$ & 0.43 \\
\hline \multicolumn{9}{|c|}{ Worst leg pain: } \\
\hline Baseline & 73 & $7.9(1.7)$ & - & 72 & $7.8(2.0)$ & - & - & - \\
\hline 1 month & 73 & $4.9(3.1)$ & $-3.0(2.8)$ & 72 & $5.8(3.0)$ & $-2.0(2.9)$ & 0.9 (0.0 to 1.9) & 0.04 \\
\hline 3 months & 73 & $5.2(3.4)$ & $-2.7(3.2)$ & 72 & $5.5(3.4)$ & $-2.3(3.5)$ & $0.3(-0.7$ to 1.4$)$ & 0.54 \\
\hline \multicolumn{9}{|c|}{ Average back pain: } \\
\hline Baseline & 73 & $5.0(2.6)$ & - & 72 & $4.7(2.4)$ & - & - & - \\
\hline 1 month & 73 & $3.5(2.6)$ & $-1.5(1.9)$ & 72 & $3.6(2.6)$ & $-1.1(2.3)$ & $0.3(-0.4$ to 0.9$)$ & 0.45 \\
\hline 3 months & 73 & $3.9(2.7)$ & $-1.1(2.4)$ & 72 & $3.7(2.5)$ & $-1.0(2.4)$ & $-0.1(-0.8$ to 0.6$)$ & 0.85 \\
\hline \multicolumn{9}{|c|}{ Worst back pain: } \\
\hline Baseline & 73 & $7.0(2.6)$ & - & 72 & $7.0(2.9)$ & - & - & - \\
\hline 1 month & 73 & $5.1(2.9)$ & $-1.9(2.4)$ & 72 & $5.4(3.2)$ & $-1.6(2.6)$ & $0.3(-0.4$ to 1.1$)$ & 0.38 \\
\hline 3 months & 72 & $5.6(3.2)$ & $-1.4(2.9)$ & 72 & $5.6(3.1)$ & $-1.4(2.8)$ & $0.0(-0.8$ to 0.9$)$ & 0.91 \\
\hline \multicolumn{9}{|c|}{ Oswestry disability scoreł: } \\
\hline Baseline & 73 & $39.8(15.3)$ & - & 72 & $39.8(14.7)$ & - & - & - \\
\hline 1 month & 73 & $32.6(18.3)$ & $-7.3(12.5)$ & 72 & $29.6(16.0)$ & $-10.2(14.5)$ & $-2.9(-7.2$ to 1.3$)$ & 0.18 \\
\hline 3 months & 73 & $33.6(19.4)$ & $-6.2(15.8)$ & 72 & $29.6(16.3)$ & $-10.2(16.7)$ & $-3.9(-9.0$ to 1.1$)$ & 0.12 \\
\hline
\end{tabular}

*Data for missing 1 month and 3 months outcomes including pain scores, Oswestry disability scores imputed by last observed outcome carried forward. Numerical rating scores for pain are based on 0-10 numerical rating scales, with 0 indicating no pain and 10 indicating severe pain.

tDifferences for pain and Oswestry disability scores adjusted for baseline values. Negative coefficients favor gabapentin group. Positive coefficients favor epidural steroid injection group.

$\$ 10$ question survey used to assess function in people with low back and/ or leg pain, in which higher scores indicate greater levels of disability. ${ }^{26}$ 


\begin{tabular}{|c|c|c|c|c|c|}
\hline & \multicolumn{2}{|c|}{$\begin{array}{l}\text { Epidural steroid } \\
\text { injection }\end{array}$} & \multicolumn{2}{|c|}{ Gabapentin } & \multirow[b]{2}{*}{$\begin{array}{l}\text { P value for } \\
\text { comparison }\end{array}$} \\
\hline & $\begin{array}{l}\text { No of } \\
\text { patients }\end{array}$ & No (\%) & $\begin{array}{l}\text { No of } \\
\text { patients }\end{array}$ & No (\%) & \\
\hline \multicolumn{6}{|l|}{ Reduction in drug treatment*: } \\
\hline 4 weeks & 67 & $40(60)$ & 65 & $32(49)$ & 0.23 \\
\hline 12 weeks & 40 & $23(58)$ & 30 & $14(47)$ & 0.37 \\
\hline \multicolumn{6}{|l|}{ Global perceived effect (positive)t: } \\
\hline 1 month & 73 & $49(67)$ & 72 & $41(57)$ & 0.21 \\
\hline 3 months & 73 & $33(45)$ & 72 & $24(33)$ & 0.14 \\
\hline \multicolumn{6}{|l|}{ Composite outcome (positive)†‡: } \\
\hline 1 month & 73 & $48(66)$ & 72 & $33(46)$ & 0.02 \\
\hline 3 months & 73 & $27(37)$ & 72 & $21(29)$ & 0.32 \\
\hline $\begin{array}{l}\text { Proceeded to surgery within year } \\
\text { of enrollment }\end{array}$ & 72 & $9(13)$ & 69 & $10(14)$ & 0.73 \\
\hline \multicolumn{6}{|c|}{$\begin{array}{l}\text { *Reduction in analgesics corresponds to }>20 \% \text { reduction in opioid use or complete cessation of non-opioid } \\
\text { analgesics. Patients who were not on pain drugs were excluded from this analysis. } \\
+ \text { Missing data for } 1 \text { month and } 3 \text { months imputed by last observed outcome carried forward. } \\
\ddagger>2 \text { point decrease in average leg pain coupled with positive global perceived effect without additional } \\
\text { procedural or non-rescue pharmacological interventions. }\end{array}$} \\
\hline
\end{tabular}

personnel or non-service members at one month (odds ratio $6.7,95 \%$ confidence interval 1.8 to 24.6 ; $\mathrm{P}=0.004$ ). Injection at $\mathrm{S} 1$ was associated with a greater reduction in leg pain than at other levels $(-0.7,-0.1$ to $-1.2 ; \mathrm{P}=0.02)$ but failed to reach significance when we adjusted for multiple comparisons. We found no associations among the primary or composite outcomes at one month based on etiology (such as stenosis $v$ herniated disc), pain duration $\geq 3$ months, injection type (transforaminal epidural steroid injections for unilateral pain $v$ interlaminar epidural steroid injections for bilateral pain), smoking status, presence of psychiatric disease, obesity, age, sex, or dose of gabapentin. In post hoc adjustments for sex, the difference between groups in reduction of worst leg pain favoring epidural steroid injections was no longer significant $(0.3,-0.8$ to 1.4 ; $\mathrm{P}=0.05)$.

\section{Adverse events}

The proportion of patients reporting one or more adverse events from the injection was $8 \%(n=6)$ in the epidural steroid injection group and $10 \%(n=7)$ in the gabapentin group $(\mathrm{P}=0.75)$. The proportion of patients reporting one or more adverse events from drug treatment was $42 \%(n=30)$ in the epidural steroid injection group and $51 \%(n=37)$ in the gabapentin group $(\mathrm{P}=0.24$; table 4).

\section{Blinding}

We assessed blinding at two time points: immediately after the procedure to assess blinding for real epidural steroid injections and at the first follow-up to ensure blinding for real gabapentin. Immediately after the baseline procedure, patients were unaware of assigned treatments (James blinding index 0.75, 95\% confidence interval 0.69 to $0.80 ; \mathrm{P}=1.0$; Bing blinding index 0.07 $(-0.07$ to 0.21$)$ in the epidural steroid injections group and $-0.24(-0.38$ to -0.09$)$ in gabapentin group), indicating successful blinding. At one month, the overall success of blinding was maintained (James blinding index $0.56,0.49$ to $0.63 ; \mathrm{P}=0.93$ ), though there was a trend towards better insight into treatment assignment for the gabapentin group (Bing blinding index 0.08 $(-0.07$ to 0.25$)$ in epidural steroid injection group and 0.19 (0.03 to 0.36$)$ in gabapentin group).

\section{Discussion \\ Principal findings and study rationale}

In people with lumbosacral radicular pain randomized to epidural steroid injections or gabapentin, we found that although there were some small differences in favor of the injections at one month, there were no significant differences for our primary outcome measure (average leg pain one and three months), and the differences observed mostly disappeared at three months. Although only a small percentage of our patients had spinal stenosis, our findings are consistent with a recent multicenter study that found modest short term benefit for epidural steroid injections for this condition. ${ }^{44}$ In our study we compared epidural steroid injections with epidural local anesthetic, which a systematic review showed was superior to soft tissue control injections (that is, not a placebo). ${ }^{45}$ We elected to use a "true placebo" (intramuscular injection), which is more difficult to blind but unlikely to provide benefit, and included patients with both spinal stenosis and herniated disc. Broad inclusion criteria enhance generalization and are consistent with guidelines on comparative effectiveness research. ${ }^{4647}$

The rationale for this comparative efficacy study is that there are well over 50 published clinical trials epidural steroid injections or adjuvants compared with placebo for radiculopathy, but none that compared one treatment with another. In accordance with the US Department of Health and Human Services recommendation to increase and improve comparative effectiveness research, ${ }^{46}$ we decided to compare two of the most common treatments for lumbosacral radicular pain in a double blind fashion. ${ }^{46}$

\section{Comparison with other studies}

Results of placebo controlled studies evaluating gabapentinoids and other membrane stabilizers for radiculopathy are mixed, indicating a probable small effect size. ${ }^{48}$ This suggests that differences between groups are unlikely to represent a large treatment effect. Although myriad reviews on epidural steroid injections have yielded disparate conclusions, recent systematic and evidence based reviews have indicated that any stand alone treatment effect for epidural steroid injections is likely to be modest and short lived. ${ }^{122}$

In a recent open label three arm comparative effectiveness study pitting a series of epidural steroid injections against conservative therapy consisting of pharmacotherapy (gabapentin and/or nortriptyline) and physical therapy, and the combination of the two, it was found that combination treatment with epidural steroid injections plus drugs and physical therapy provided superior benefit to stand alone treatment on some 


\begin{tabular}{|c|c|c|c|}
\hline Adverse event & $\begin{array}{l}\text { Epidural steroid injection } \\
\text { group }(n=73)\end{array}$ & $\begin{array}{l}\text { Gabapentin group } \\
(n=72)\end{array}$ & $P$ value \\
\hline \multicolumn{4}{|l|}{ Related to injection } \\
\hline Injection received & Epidural steroid injections & Sham injection & - \\
\hline$\geq 1$ event*$^{\star}$ & $6(8)$ & $7(10)$ & 0.75 \\
\hline Total adverse events (event rate)† & $6(0.08)$ & $9(0.13)$ & 0.42 \\
\hline \multicolumn{4}{|l|}{ Reported symptoms or events: } \\
\hline Excessive pain & $2 \ddagger$ & $4 \ddagger$ & - \\
\hline Fever, infection, or both & 2 & 0 & - \\
\hline Falls & $1 \neq$ & 0 & - \\
\hline Vasovagal & 0 & $2 \ddagger$ & - \\
\hline Other§ & 1 & 3 & - \\
\hline \multicolumn{4}{|l|}{ Related to drug treatment } \\
\hline Treatment received & Sham pills & Gabapentin pills & - \\
\hline Mean (SD) dose (mg) & $2132.9(609.4)$ & $2095.8(678.3)$ & 0.73 \\
\hline \multicolumn{4}{|l|}{ Complianceף: } \\
\hline None & $6(8)$ & $8(11)$ & \multirow[t]{3}{*}{0.68} \\
\hline Partial (50-89\%) & $11(15)$ & $8(11)$ & \\
\hline Full (>90\%) & $55(76)$ & $56(78)$ & \\
\hline$\geq 1$ event $* \mathfrak{q}$ & $30(42)$ & $37(51)$ & 0.24 \\
\hline Total adverse events (event rate) ${ }^{\star} \boldsymbol{q}$ & $45(0.63)$ & $50(0.69)$ & 0.61 \\
\hline \multicolumn{4}{|l|}{ Reported symptoms or events $\mathbb{\text { : }}$} \\
\hline Sedation/fatigue & $8(11)$ & $13(18) \ddagger$ & - \\
\hline Cognitive & $5(7)$ & $7(10) \ddagger$ & - \\
\hline Weight gain & $4(6)$ & $7(10) \ddagger$ & - \\
\hline Headache & $4(6)$ & $1(1)$ & - \\
\hline Gastrointestinal & $13(18)$ & $8(11) \ddagger$ & - \\
\hline Swelling & $0(0)$ & $3(4) \neq$ & - \\
\hline Other $^{\star *}$ & $11(15)$ & $11(15) \ddagger$ & - \\
\hline \multicolumn{4}{|c|}{ 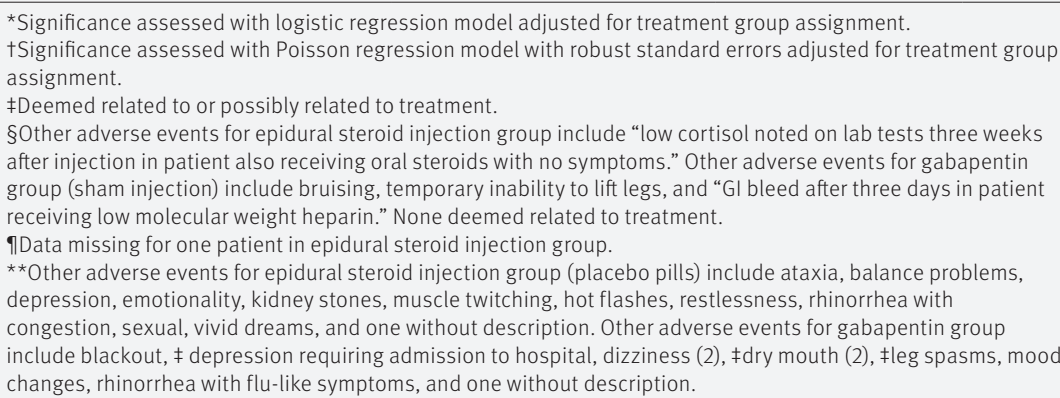 } \\
\hline
\end{tabular}

outcome measures. ${ }^{26}$ In some respects, the open label format and inclusion of a multimodal treatment approach might better reflect "real life" circumstances, though they preclude the evaluation of efficacy.

\section{Explanation of findings}

There are several possible explanations for our findings. The first is that both treatments are equally effective, but the effects dissipate over time. Unlike studies of epidural steroid injections that often follow patients for up to one year, ${ }^{49-54}$ few studies have examined the long term effectiveness of gabapentin, but those that have indicate that the beneficial effects for neuropathic pain are most pronounced early on during treatment. ${ }^{55}$ ${ }^{56} \mathrm{~A}$ second hypothesis is that neither treatment is effective, and the benefits observed were caused by a placebo response or the natural course of the disease. Those with chronic radiculopathy, however, are less likely than those with shorter duration of symptoms to spontaneously improve or respond to treatment. ${ }^{57}$ A third possibility is that epidural steroid injections are superior to gabapentin, but the relatively small sample size, the use of only one injection, treatment blinding, and our failure to reinforce the short term benefit with physical therapy rendered three month differences indistinguishable. In their effectiveness study that compared a series of epidural steroid injections, neuropathic adjuvants plus physical therapy, and combination therapy for cervical radiculopathy, Cohen and colleagues reported that the better outcomes in the combination group might have been attributable to the ability of physical therapy to reinforce the short term gains afforded by procedures. ${ }^{26}$

\section{Strengths and limitations}

The main strength of our study is that we compared two of the most commonly used treatments for lumbosacral radiculopathy pain in a double blind fashion at institutions that reflect the gamut of settings in which patients might seek treatment. There are several limitations to our study, including the primary outcome being measured at one month, which was necessary because we allowed those with an unsuccessful outcome to seek other treatments, and the lack of a true placebo group, which renders the assay sensitivity questionable. Without a true placebo group, one cannot assess the true efficacy of the two treatments. A third limitation is that we did not permit repeat epidural steroid injections or allow combination drug treatment. Studies have shown there is little basis for a rote "series" of epidural steroid injections, though some might benefit from repeat injections, which are often performed in clinical practice. ${ }^{1263244545859}$ Similarly, randomized studies have shown that combination treatment with drugs that include gabapentinoids could provide superior relief for neuropathic and low back pain compared with treatment with a single agent. ${ }^{60}$ A fourth limitation inherent in our design is that blinding of participants might have altered our findings. "Blinding" is not a tenet of comparative effectiveness research, which seeks to determine the best treatment in "real world" conditions. The placebo effect is especially powerful for subjective measures such as pain and stronger for procedures than for pills, which might have mitigated any "real world" differences between treatments. ${ }^{6162}$ A final limitation is our broad inclusion criteria, which included patients taking opioids and those with herniated disc and spinal stenosis. These conditions are characterized by slightly different pathophysiological mechanisms and might have different natural outcomes. A larger study would be needed to determine whether certain patients (such as those with herniated disc versus spinal stenosis) or treatments (transforaminal versus interlaminar epidural steroid injections) experience better outcomes than others. In practice, patients generally receive epidural steroid injections and/or adjuvants regardless of the etiology of their neuropathic pain. In clinical trials, most epidural steroid injection 
studies $^{1224-2632495153}$ and all gabapentinoid studies ${ }^{17-21}$ included both etiologies, with most studies finding no difference in outcomes with epidural steroid injection $^{12}$ or gabapentinoid (R Baron, personal communication, 2014) 2021 between people with stenosis and disc herniation.

\section{Generalizability}

These results are readily generalizable to primary care settings, pain clinics, and spine surgery centers, where practitioners are often faced with the question about the best non-operative way to manage lumbosacral radicular pain. Future studies might include both placebo and combination groups (for example, factorial design), allow for multiple injections and drugs, and require physical therapy in an effort to determine whether any observed benefit could be prolonged. The logistical and ethical obstacles in designing such studies (such as blinding multiple drugs or performing multiple sham injections in patients who fail to respond to the first one), however, will make them difficult to execute.

\section{Conclusions and policy implications}

Gabapentin and epidural steroid injections used to treat lumbosacral radicular pain both resulted in modest improvements in pain and function, which persisted through three months. Although some differences favored epidural steroid injections, these tended to be small and transient. The similar outcomes between treatment groups on most measures suggest that a trial with neuropathic drugs might be a reasonable first line treatment option.

\section{AUTHOR AFFILIATIONS}

'Blaustein Pain Treatment Center, Department of Anesthesiology, Johns Hopkins School of Medicine, Baltimore, MD, USA

${ }^{2}$ Walter Reed National Military Medical Center, Bethesda, MD, USA

${ }^{3}$ Pain Medicine Division, Department of Anesthesiology, Naval Medical Center-San Diego, USA

${ }^{4}$ Department of Anesthesiology, Massachusetts General Hospital, Boston, MA, USA

Interdisciplinary Pain Medicine, Department of Surgery, Landstuhl, Regional Medical Center, Landstuhl, Germany

${ }^{6}$ Pain Medicine Service Department of Anesthesiology, Louis Stokes Cleveland VA Medical Center, Case Western University, Cleveland, $\mathrm{OH}$, USA

${ }^{7}$ Anesthesia Service, Department of Surgery, Walter Reed National Military Medical Center, Bethesda, MD, USA

${ }^{8}$ Department of Neurology, District of Columbia VA Hospital, Washington DC, MD, USA

${ }^{9}$ Department of Medicine, George Washington University, Washington DC, MD, USA

10Pain Medicine Division, Department of Anesthesiology, Case Western Reserve School of Medicine, Cleveland, OH, USA

${ }^{11}$ Interdisciplinary Pain Management Clinic, Department of Anesthesiology, San Antonio Military Medical Center, San Antonio, TX, USA

12Pain Medicine Fellowship Program, Department of Anesthesiology, San Antonio Military Medical Center, San Antonio, TX, USA

${ }^{13}$ Walter Reed National Military Medical Center, Bethesda, MD, USA

14Pain Medicine Division, Department of Anesthesiology, Penn State Hershey Medical Center, Hershey, PA, USA
${ }^{15}$ Department of Anesthesiology, Johns Hopkins School of Medicine, Baltimore, MD, USA

16Departments of Anesthesiology and Neurology, Penn State Hershey Medical Center, Hershey, PA, USA

${ }^{17}$ Department of Physical Medicine and Rehabilitation, Walter Reed National Military Medical Center and Uniformed Services University of the Health Sciences, Bethesda, MD, USA

We thank all patients for their participation in this study, and the project manager (Brad Isaacson), overall pharmacy coordinator (Manisha Hong), Benny Morlando (nurse at Walter Reed), and the pharmacist at Walter Reed National Military Medical Center (Parvaneh Moussavian-Yousefi) for their assistance.

The opinions or assertions contained herein are the private views of the authors and are not to be construed as official or as reflecting the views of the Department of the Army or the Department of Defense.

Contributors: SPC designed the study, wrote protocol, served as overall principal investigator, performed treatments, and wrote and reviewed the manuscript. SH, YV, RLW, KBG, and ZZ (site principal investigators) performed treatments and reviewed the manuscript. SRG, VG, and EV assisted with protocol adaptation for individual sites, performed treatments, and reviewed the manuscript. MAW and CK, research nurses (CK was chief research nurse), collected data and assisted with protocol adaptations and submissions. MCB helped to write the manuscript and carried out statistical analyses. PFP helped with design study, funding source, and critical review of manuscript. SPC and PFP are guarantors.

Funding: This study was funded by a congressional grant from the Center for Rehabilitation Sciences Research, Bethesda, MD. The funders paid for personnel, medications, and procedures.

Competing interests: All authors have completed the Unified Competing Interest form at www.icmje.org/coi_disclosure.pdf (available on request from the corresponding author) and declare: SPC serves as a consultant for Semnur Pharmaceuticals; no other relationships or activities that could appear to have influenced the submitted work.

Ethical approval: This study was approved by the internal review boards at all eight participating institutions, and informed consent was given by all participants.

Data sharing statement: Statistical code, and limited anonymized dataset will be available pending permission from the US Army by contacting the corresponding author.

Transparency: SPC affirms that the manuscript is an honest, accurate, and transparent account of the study being reported; that no important aspects of the study have been omitted; and that any discrepancies are disclosed.

This is an Open Access article distributed in accordance with the Creative Commons Attribution Non Commercial (CC BY-NC 4.0) license, which permits others to distribute, remix, adapt, build upon this work non-commercially, and license their derivative works on different terms, provided the original work is properly cited and the use is non-commercial. See: http://creativecommons.org/licenses/ by-nc/4.0/.

1 US Burden of Disease Collaborators. The state of US health, 1990-2010: burden of diseases, injuries, and risk factors. JAMA 2013;310:591-608.

2 Hoy D, Bain C, Williams $G$ et al. A systematic review of the global prevalence of low back pain. Arthritis Rheum 2012;64:2028-37.

3 Juniper M, Le T, Mladsi D. The epidemiology, economic burden, and pharmacological treatment of chronic low back pain in France, Germany, Italy, Spain and the UK: a literature-based review. Expert Opin Pharmacother 2009;10:2581-92.

4 Crow W, Willis D. Estimating cost of care for patients with acute low back pain: a retrospective review of patient records. I Am Osteopath Assoc 2009;109:229-33.

5 Cohen SP, Mao J. Mechanisms of neuropathic pain and their clinical implications. BM/ 2014:348:f7656.

6 Bennett M. The LANSS pain scale: the Leeds assessment of neuropathic symptoms and signs. Pain 2001;92:147-57.

7 Freynhagen R, Baron R, Gockel U, et al. painDETECT: a new screening questionnaire to identify neuropathic components in patients with back pain. Curr Med Res Opin 2006;22:1911-20.

8 El Sissi W, Arnaout A, Chaarani M, et al. Prevalence of neuropathic pain among patients with chronic low-back pain in the Arabian Gulf Region assessed using the Leeds assessment of neuropathic symptoms and signs pain scale. J Int Med Res 2010;38:2135-45.

9 Beith I, Kemp A, Kenyon J, et al. Identifying neuropathic back and leg pain: a cross-sectional study. Pain 2011:152:1511-6. 
10 Kaki A, El-Yaski A, Youseif E. Identifying neuropathic pain among patients with chronic low-back pain: use of the Leeds assessment of neuropathic symptoms and signs pain scale. Reg Anesth Pain Med 2005;30:422-8.

11 Hassan A, Saleh H, Baroudy Y, et al. Prevalence of neuropathic pain among patients suffering from chronic low back pain in Saudi Arabia. Saudi Med / 2004:25:1986-90.

12 Cohen SP, Jamison D, Bicket M, et al. Epidural steroids: a comprehensive, evidence-based review. Reg Anesth Pain Med 2013;38:175-200.

13 Hill JC, Konstantinou K, Egbewale BE, et al. Clinical outcomes among low back pain consulters with referred leg pain in primary care. Spine (Phila Pa 1976) 2011;36:2168-75.

14 Jacobs WC, Rubinstein SM, Koes B, et al. Evidence for surgery in degenerative lumbar spine disorders. Best Pract Res Clin Rheumatol 2013;27:673-84

15 Manchikanti L, Falco FJ, Singh V, et al. Utilization of interventional techniques in managing chronic pain in the Medicare population: analysis of growth patterns from 2000 to 2011. Pain Physician 2012:15:E969-82.

16 Hopwood M, Abram S. Factors associated with failure of lumbar steroids. Reg Anes 1993;18:238-43.

17 McCleane GJ. Does gabapentin have an analgesic effect on background, movement and referred pain? A randomized, double-blind, placebo controlled study. Pain Clinic 2001;13:103-7.

18 Yildirim K, Sisecioglu M, Karatay S, et al. The effectiveness of gabapentin in patients with chronic radiculopathy. Pain Clinic 2003;15:213-8

19 Romano CL, Romanò D, Bonora C, et al Pregabalin, celecoxib, and their combination for treatment of chronic low-back pain. J Orthopaed Traumatol 2009;10(4):185-91.

20 Baron R, Martin-Mola E, Müller M, et al. Effectiveness and safety of tapentadol prolonged release (PR) versus a combination of tapentadol PR and pregabalin for the management of severe, chronic low back pain with a neuropathic component: a randomized, double-blind, phase 3b study. Pain Pract 2014; doi:10.1111/ papr.12200

21 Baron R, Freynhagen R, Tölle TR, et al; A0081007 Investigators. The efficacy and safety of pregabalin in the treatment of neuropathic pain associated with chronic lumbosacral radiculopathy. Pain 2010;150:420-7.

22 Pinto RZ, Maher CG, Ferreira ML, et al. Epidural corticosteroid injections in the management of sciatica: a systematic review and meta-analysis. Ann Intern Med 2012;157:865-77.

23 Brouwers MC, Thabane L, Moher D, et al. Comparative effectiveness research paradigm: implications for systematic reviews and clinical practice guidelines. J Clin Oncol 2012;30:4202-7.

24 Laiq N, Khan MN, Iqbal MJ, et al. Comparison of epidural steroid injections with conservative management in patients with lumbar radiculopathy. J Coll Physicians Surg Pak 2009;19:539-43.

25 Dincer U, Kiralp MZ, Cakar E, et al. Caudal epidural injection versus non-steroidal anti-inflammatory drugs in the treatment of low back pain accompanied with radicular pain. Joint Bone Spine 2007;74:467-71

26 Cohen SP, Hayek S, Semenov Y, et al. Epidural steroid injections, conservative treatment or combination treatment for cervical radiculopathy: a multi-center, randomized, comparative-effectiveness study. Anesthesiology 2014:121:1045-55.

27 Dunn AS, Julian T, Formolo LR, et al. Preliminary analysis of posttraumatic stress disorder screening within specialty clinic setting for OIF/OEF veterans seeking care for neck or back pain. J Rehabil Res Dev 2011;48:493-502.

28 Geisser ME, Roth RS, Robinson ME. Assessing depression among persons with chronic pain using the Center for Epidemiological Studies-Depression Scale and the Beck Depression Inventory: a comparative analysis. Clin J Pain 1997;13:163-70

29 Botwin K, Natalicchio J, Brown LA. Epidurography contrast patterns with fluoroscopic guided lumbar transforaminal epidural injections: a prospective evaluation. Pain Physician 2004:7:211-5.

30 Furman MB, Butler SP, Kim RE, et al. Injectate volumes needed to reach specific landmarks in s1 transforaminal epidural injections. Pain Med 2012;13:1265-74

31 Fairbank JC, Couper J, Davies JB, et al. The Oswestry low back pain disability questionnaire. Physiotherapy 1980;66:271-3.

32 Cohen SP, White RL, Kurihara C, et al. Epidural steroids, etanercept, or saline in subacute sciatica: a multicenter randomized trial. Ann Intern Med 2012;156:551-9.

33 Moore RA, Wiffen PJ, Derry S, et al. Gabapentin for chronic neuropathic pain and fibromyalgia in adults. Cochrane Database Syst Rev 2014;4:CD007938.

34 Förster M, Mahn F, Gockel U, et al. Axial low back pain: one painful area--many perceptions and mechanisms. PLoS One 2013;8:e68273.

35 Cohen SP, Raja SN. Pathogenesis, diagnosis and treatment of lumbar zygapophysial (facet) joint pain. Anesthesiology 2007:106:591-614.
36 Dworkin RH, Turk DC, Wyrwich KW, et al. Interpreting the clinical importance of treatment outcomes in chronic pain clinical trials: IMMPACT recommendations. J Pain 2008:9:105-21.

37 Ackerman WE 3rd, Ahmad M. The efficacy of lumbar epidural steroid injections in patients with lumbar disc herniations. Anesth Analg 2007:104:1217-22.

38 Ghahreman A, Ferch R, Bogduk N. The efficacy of transforaminal injection of steroids for the treatment of lumbar radicular pain. Pain Med 2010;11:1149-68.

39 Lane P. Handling drop-out in longitudinal clinical trials: a comparison of the LOCF and MMRM approaches. Pharm Stat 2008;7:93-106.

40 James KE, Bloch DA, Lee KK, et al. An index for assessing blindness in a multicentre clinical trial: dsulfiram for alcohol cessation-a VA cooperative study. Stat Med 1996;15:1421-34.

41 Bang H, Ni L, Davis CE. Assessment of blinding in clinical trials. Control Clin Trials 2004;25:143-56.

42 Skljarevski V, Ossanna M, Liu-Seifert H, et al. A double-blind, randomized trial of duloxetine versus placebo in the management of chronic low back pain. Eur J Neurol 2009;16:1041-8.

43 Rice AS, Maton S; Postherpetic Neuralgia Study Group. Gabapentin in postherpetic neuralgia: a randomised, double blind, placebo controlled study. Pain 2001;94:215-24.

44 Friedly JL, Comstock BA, Turner JA, et al. A randomized trial of epidural glucocorticoid injections for spinal stenosis. N Engl J Med 2014;371:11-21

45 Bicket M, Gupta A, Brown C, et al. Epidural injections for spinal pain: A systematic review and meta-analysis evaluating the "control" injections in randomized controlled trials. Anesthesiology 2013;119:907-31.

46 Department of Health and Human Services Federal Coordinating Council on Comparative-Effectiveness Research. Report to the President and the Congress. Presented on June 30, 2009. www. tuftsctsi.org/ /media/Files/CTSI/Library\%20Files/FCC\%20for\%20 CER\%20Rpt\%20to\%20Pres\%20and\%20Congress 063009.ashx.

47 Brouwers MC, Thabane L, Moher D, et al. Comparative effectiveness research paradigm: Implications for systematic reviews and clinical practice guidelines. J Clin Oncol 2012;30:4202-7.

48 Pinto RZ, Maher CG, Ferreira ML, et al. Drugs for relief of pain in patients with sciatica: systematic review and meta-analysis. $B M$ J 2012;344:e497.

49 Iversen T, Solberg TK, Romner B, , et al. Effect of caudal epidural steroid or saline injection in chronic lumbar radiculopathy: multicentre, blinded, randomised controlled trial. BMJ 2011;343:d5278

50 Arden NK, Price C, Reading।, et al. WEST Study Group. A multicentre randomized controlled trial of epidural corticosteroid injections for sciatica: the WEST study. Rheumatology (Oxford) 2005;44:1399-406.

51 Karppinen J, Malmivaara A, Kurunlahti M, et al. Periradicular infiltration for sciatica: a randomized controlled trial. Spine (Phila Pa 1976) 2001;26:1059-67.

52 Sayegh FE, Kenanidis El, Papavasiliou KA, et al. Efficacy of steroid and nonsteroid caudal epidural injections for low back pain and sciatica: a prospective, randomized, double-blind clinical trial. Spine (Phila Pa 1976) 2009;34:1441-7.

53 Vad VB, Bhat AL, Lutz GE, et al. Transforaminal epidural steroid injections in lumbosacral radiculopathy: a prospective randomized study. Spine (Phila Pa 1976) 2002;27:11-6.

54 Riew KD, Park JB, Cho YS, et al. Nerve root blocks in the treatment of lumbar radicular pain. A minimum five-year follow-up. J Bone Joint Surg Am 2006;88:1722-5.

55 Johnson P, Becker L, Halpern R, et al. Real-world treatment of post-herpetic neuralgia with gabapentin or pregabalin. Clin Drug Investig 2013;33:35-44

56 Liedgens H, Hertel N, Gabriel A, et al. Cost-effectiveness analysis of a lidocaine $5 \%$ medicated plaster compared with gabapentin and pregabalin for treating postherpetic neuralgia: a German perspective. Clin Drug Investig 2008;28:583-601.

57 Haugen AJ, Brox JI, Grøvle L, et al. Prognostic factors for non-success in patients with sciatica and disc herniation. BMC Musculoskelet Disord 2012;13:183.

58 Novak S, Nemeth WC, NovakS, et al. The basis for recommending repeating epidural steroid injections for radicular low back pain: a literature review. Arch Phys Med Rehabil 2008;89:543-52.

59 Carette S, Leclaire R, Marcoux S, et al. Epidural corticosteroid injections for sciatica due to herniated nucleus pulposus. N EnglJ Med 1997;336:1634-40.

60 Chaparro LE, Wiffen PJ, Moore RA, et al. Combination pharmacotherapy for the treatment of neuropathic pain in adults. Cochrane Database Syst Rev 2012;7:CD008943.

61 Kaptchuk TJ, Stason WB, Davis RB, et al. Sham device v inert pill: randomized controlled trial of two placebo treatments. BMJ 2006;332:391-7.

62 Koshi EB, Short CA. Placebo theory and its implications for research and clinical practice: a review of the recent literature. Pain Pract 2007;7:4-20

(C) BMJ Publishing Group Ltd 2015 